\title{
Stress Management in Parents of Children with Diabetes Type 1: A Randomized Controlled Trial
}

\author{
Niki S. Pateraki ${ }^{1}$, Evaggelia Mantzourani ${ }^{2}$, Panagiota P. Darvyri ${ }^{1}{ }^{*}$, Evangelos C. Alexopoulos ${ }^{1}$, \\ Liza Varvogli', Dimitrios Mamoulakis², Darviri Christina ${ }^{1 \#, ~ G e o r g e ~ P . ~ C h r o u s o s ~}{ }^{1,3 \#}$ \\ ${ }^{1}$ Postgraduate Course Science of Stress and Health Promotion, School of Medicine, University of Athens, \\ Athens, Greece \\ ${ }^{2}$ General Hospital of Heraklion, Crete, Greece \\ ${ }^{3}$ First Department of Pediatrics, Children's Hospital Aghia Sofia, School of Medicine, University of Athens, \\ Athens, Greece \\ Email: *pandarviri@yahoo.gr
}

Received 8 April 2015; accepted 27 June 2015; published 30 June 2015

Copyright (C) 2015 by authors and Scientific Research Publishing Inc.

This work is licensed under the Creative Commons Attribution International License (CC BY).

http://creativecommons.org/licenses/by/4.0/

(c) (i) Open Access

\section{Abstract}

Parents of children with diabetes type 1 (DT1) usually mention high stress levels as they have to cope with multiple demands in everyday life. Simple stress management techniques can be administered in everyday life and thus may hold some benefit for parents with diabetic children. The purpose of this study was to assess to evaluate the effectiveness of a stress management program (relaxation breathing and progressive muscle relaxation/RB-PMR) in reducing symptoms of stress. Self-reported validated measures were used to evaluate perceived stress, health locus of control, daily routine, anxiety and depression. This is a pilot, randomized controlled trial. A total of 54 parents were randomly assigned to the intervention group $(n=28)$ and control group $(n=26)$. In parents in the intervention group perceived stress, symptoms of depression and anxiety were significantly decreased after 8 weeks of the relaxation program $(0.017,0.044$ and 0.006$)$. RB-PMR practice was associated with changes in physical and psychological symptoms of parents with children with DT1. Future studies should extend by incorporating more objective clinical and laboratory outcomes.

\section{Keywords}

Diabetes Type 1, Parents, Stress, Relaxation Techniques, Coping

\footnotetext{
${ }^{*}$ Corresponding author.

"These authors contributed equally and shared last authorship.
}

How to cite this paper: Pateraki, N. S., Mantzourani, E., Darvyri, P. P., Alexopoulos, E. C., Varvogli, L., Mamoulakis, D., Christina, D., \& Chrousos, G. P. (2015). Stress Management in Parents of Children with Diabetes Type 1: A Randomized Controlled Trial. Psychology, 6, 1040-1050. http://dx.doi.org/10.4236/psych.2015.68101 


\section{Introduction}

Stress has long been considered an important factor to the development or aggravation of psychopathology (Selye, 1980). The dominant scientific definition is that "stress is a state in which homeostasis is actually threatened or perceived to be so". The irregular adaptive response from the stress system can conduct a state of distress, cacostasis or allostatic overload, all of which enunciate the admission of pathology and disease (Chrousos, 2009; McEwen, 1998). Coping has been prescribed in psychological terms by Susan Folkman and Richard Lazarus as "a consecutively change in cognitive and behavioral efforts to handle specific external and/or internal requirements that are appraised as exacting” or "trascending the limits of the person” (Cohen \& Kessler, 1997; Cummings et al., 1991). Coping in this way is an aware try to solve personal and interpersonal problems, and attempting to master, minimize or suffer stress or impact.

Stress of caregivers is caused by a hormone increase for extended periods. Caregivers also experience a depressive and exhausting emotional state because of the provided care to their lovely persons. There are also "double-duty caregivers" that they provide their care working in the healthcare field and they also feel obligated to do the same at home. This exhausted role can cause a reduction to their physical and mental health. We also consider that a part of the stress that caregivers experience is caused from how you feel about the job. For example if somebody does not like or want to be a caregiver, actually experience higher levels of stress. People who provide care for a friend or family member with a long-term disease exist a chronic stress. Also, caregiving has been shown to influence on the immune system. For example caregivers to Alzheimer's patients was found to be more depressed, they showed lower levels of life satisfaction and higher EBV antibody titresand and lower percentages of $\mathrm{T}$-cells and $\mathrm{T}_{\mathrm{H}}$ cells than the comparison samples (Esterling et al., 1996). Caregiving has also been shown to have a negative affection on wound repair (Kiecolt-Glaser et al., 1995).

Symptoms of caregiving stress include depression, anxiety and anger. Chronic stress can also cause health problems such as high blood pressure, diabetes and a compromised immune system (LeRoy, 2013). This influence may also reduce the caregiver's life expectancy (Schulz et al., 1999).

A recent study showed that salivary cortisol levels were in higher level for the women than for the men who work as nurses on working day. On day off the salivary cortisol levels were sufficiently lower for the men than for the women (Pires da Rocha et al., 2013). These findings are close to the results of another study which showed that women had higher salivary cortisol levels than the men did (Kunz-Ebrecht et al., 2004). But we had the opposite results for the day off. The levels of salivary cortisol were higher for the men than for the women. We can explain this observation by the excessive demands on days off.

In this way the results of this study show that on the nurse's day off stress is in lower levels. So, the results indicate that nurses are stressed while they are working.

Parenting stress is important for indicate family dysfunction and psychopathology (Abidin, 1995). Parenting stress can influence on parents and their children health. For example parenting stress was shown to preside the relationship between perceived exposure and depressive symptoms in children with T1D (Mullins et al., 2004). Also the management of a child's chronic health condition can be influenced by the parenting stress (Streisand et al., 2001). Barakat et al. (2007) found that higher levels of parenting stress was associated with greater severeness of disease and more frequent search and utilization of health care 1 year later. According to Lazarus and Folkman's (1984) stress and coping model, the Transactional, Stress and Coping Model suggest that parents' adaption and stress management methods influence to chronic illness (Thomspon et al., 1993; Thompson et al., 1992; Thompson \& Gustafson, 1996). This model has also been used in other studies of parenting stress in caregivers of children with pediatric problems (Colletti et al., 2008; Mullins et al., 2007; Streisand et al., 2001). For example proving care to a child with cancer is very demanding because these parents undertake responsibilities that they are not prepared to (Sulkers et al., 2014).

Furthermore, mothers of children with autism spectrum disorder or other neurodevelopmental disorders experience higher levels of stress, more illnesses and psychiatric problems. A total of 243 mothers of children with disabilities were randomized into either Mindfulness-Based Stress Reduction (mindfulness practice) or Positive Adult Development (positive psychology practice). These mothers had children with autism (65\%) or other disabilities (35\%). 85\% of these mothers had increased levels of stress, $48 \%$ were depressed and $41 \%$ suffered from anxiety disorders. The results showed that mothers in Mindfulness-Based Stress Reduction versus Positive Adult Development had an improvement in anxiety, depression, sleep and well-being. Mothers of children with autism spectrum disorder got less improving in anxiety but did not show any other differences (Dykens et al., 2014). 
Also parents of children with diabetes type 1 experience high levels of stress. Diabetes mellitus type 1 (T1D) is one of the most common paediatric diseases that caused from autoimmune destruction of insulin-producing beta cells of the pancreas. The classical symptoms of T1D are polyuria (frequent urination), polydipsia (increase of thirst), polyphagia (increase of hunger), and weight loss. A lot of studies have shown multiple risk factors, including genetic predisposition, diet, body size, seasonality of birth, viruses and geography, except autoimmunity (Vehik \& Dabelea, 2010; Daneman, 2005; Weinger \& Jacobson, 2001; Scott et al., 2002; Warram, 2012; Gene Phenotypes Relationships, 2011).

Concerning the pathophysiology T1D is related to a destruction of beta cells in the pancreas. Also an autoimmune response towards beta cells involving an expansion of autoreactive $C^{4+}$ and $C D^{8+} T$ helper cells, autoantibody-producing B cells and activation of the innate immune system seems to be related to the risk factors (Vehik \& Dabelea, 2010; Daneman, 2005; Weinger \& Jacobson, 2001).

The behavioral science literature has shown that behavioral problems are related to families that cope with this disease (Worral-Davies et al., 2001; Baugcum et al., 2005).

A recent research showed that one of the most demanding disease specific issues for families of children with type 1 diabetes is diet management. The results showed that parents of children with T1D experienced more parenting stress and perceived mealtime behavior more difficult than parents of children without a chronic illness. In addition, parents of children with T1D that reported higher levels of parenting stress also mentioned more problems and worries about their mealtime behavior management abilities (Scott et al., 2002). Also this study indicates that nutrition management demands maybe affiliate to low parental confidence and high levels of parental stress because mealtime behaviors were found to impact parent's feeling of confidence about protecting of their child's health. More specifically parents reported "getting worried and/or frustrated when is time to feedmy child," "not sure that my child gets enough to eat," and "not sure for my ability to manage my child's behavior during mealtime.” (Scott et al., 2002; Baughcum et al., 2005; Andreou et al., 2011; Wallston et al., 1978; Lovibond \& Lovibond, 1995; Streisand et al., 2005; Hilliard et al., 2010; Sullivan-Bolyai et al., 2004; Wennick et al. 2006). Also the results of a research on Journal of Psychosomatic Research (2001) showed that fathers that play little role in diabetes management and children perceived this as a negative situation can affect on their children's disease, and also mothers who are unsupported by fathers cannot support their children in T1D care (Worral-Davies et al., 2001).

Therapeutic psychological mediations and instructive programs can help families in coping with T1D and can also improve glycemic control. Interventions in dysfunctional family effects propably lead to improvements in family conflict and therefore to better glycemic control as all the reviewed studies support that dysfunctional family interactions, disciplinarian parenting, and diabetes-related family stress are related to worse glycemic control. Family involvement is a helpful prediction for glycemic control. When the family participates in educational programs on disease management and psychotherapeutic programs for stress management can help young patients cope with the stress of treatment and achieve better glycemic control. Therefore, physicians and medical specialists must be alert for any symptoms of stress or depression, not only in patients but also in their family members. Physicians could also complete a self-efficacy assessment test after each educating module for those families who participate in educational programs to ensure that families do not need a supplementary support.

The aim of the people that provide care to the child or teenager and his family should be the empowerment of the patients and their families for acceptance of the situation and training on the skills for successful coping of diabetes (Jaser \& Grey, 2010; Nicholson et al., 2009; Tsiouli et al., 2013).

\section{Materials and methods}

\subsection{Trial Design}

This is a two-armed, parallel group, randomized controlled study with a 1:1 allocation ratio of parents with children with diabetes type 1 to treatment or not treatment groups and at 8 weeks of follow up. After trial commencement, no change of the initial protocol (e.g. eligibility criteria) took place.

\subsection{Participants and Procedure}

The study was conducted at outpatient paediatric clinic of General Hospital of Heraklion in Crete, Greece between September 2011 and June 2012. Recruitment was performed twice per week and on the same days each 
week. During this recruitment period all participants provided fully- informed written consents to participate in the 8-week study. The study was approved by the General Hospital Scientific and Ethics Committee. All participants had children with diabetes type 1. Inclusion criteria were that participants must be 20 - 60 years of age, living in Crete and have children with diabetes type 1. Exclusion criteria included experiencing relapse and/or corticosteroid use within the last month, use of psychotropic drugs (e.g. antidepressants, benzodiazepines, antipsychotic and cannabis or other stimulants) and practice of other relaxation techniques (e.g. yoga). Participants experiencing one or more of the 43 major life events (e.g. death of spouse, job loss etc.) described in the Social Readjustment Rating Scale (SRRS) during the 8 weeks of follow up were also excluded from final analyses.

\subsection{Intervention and Related Measures}

Both the intervention and control group were provided with identical verbal and written information concerning stress and its effects on health during the ONC visit. In the intervention group, RB-PMR was administered in the form of an audio CD, consisting of 10 minutes of RB and 15 minutes of PMR. Parents were instructed to practice the guided RB-PMR CD twice a day for 8 weeks at home (for a maximum of 112 sessions). The RB technique is performed by taking deep diaphragmatic inspirations followed by slow prolonged expirations. RB is believed to increase parasympathetic activity eliciting the experience of alertness and re-invigoration. In the second phase of PMR relaxation, parents were guided through successive contractions and relaxations of different large muscle groups in a down-top orientation, as previously described by Jacobson. In each step, the parents were encouraged to focus on the difference between tension and relaxation, thus, gradually sharpening the perception of the relaxation response. PMR has been found to reduce perceived stress and salivary cortisol soon after the end of training (Pawlow \& Jones, 2005).

Compliance to daily recommended sessions was encouraged by telephone communication at the end of each week and recorded by a self-reported checklist. To provide consistency between the experimental and control groups, experienced health professionals also telephoned the control parents at the end of each week. During the telephone communication with both groups, parents were asked to report on their physical symptoms, their mood and their principal sources of stress during the last week. No counseling was provided during telephone communication with patients. At the end of 8-weeks, parents in the control group were rewarded for their participation in the study with a relaxation CD (Carlson \& Hoyle, 1993; Jacobson, 1938).

\subsection{Baseline and Outcome Measures}

Socio-demographic and disease-related variables. These variables included age, gender, marital status, educational status, income and smoking status.

Perceived Stress Scale (PSS): The PSS is a self-reported 14-item measure of the degree to which situations in an individual's life are appraised as stressful. For this purpose, respondents rated the frequency of their feelings and thoughts over the previous month in a five-point Likert type scale (from $0=$ never to $4=$ very often). There are seven positive and seven negative items and the total score was calculated by summing up each score after reversing all the positive items (min. total score $=0$, max. total score $=56$ ). Higher scores indicate higher level of perceived stress by the individual during the last month. PSS measurement was performed at the beginning of the trial and at the end of the 8-week of follow-up (Andreou et al., 2011; Cohen, Mermelstein, \& Kamarck 1983).

Health Locus of Control scale (HLC): Health locus of control was measured using the 18-item Health Locus of Control Scale (HLC) developed by Wallston and colleagues (1978). The respondents expressed their level of agreement to 18 statements in a 6-point Likert type scale (from $1=$ strongly disagree to $6=$ strongly agree). The scale is built upon three 6-item subscales, namely: "internal health locus of control" (HLC1), "external health locus of control" (HLC2) and "chance" (HLC3). The internal health locus of control (HLC1) measures the degree in which the individual believes that he/she is responsible for his/her health status. The external health locus of control (HLC2) and chance (HLC3) represent the extent in which other people (such as medical doctors) or chance, respectively, are perceived by individuals as the main health determinants. After summing up answers for each subscale, higher scores indicate higher strength of each type of health belief (total score range 6-36 for each subscale). HLC measurements were made at baseline and at the end of the 8 weeks. The instrument has been standardized for Greek populations (Wallston, Wallston, \& DeVellis, 1978).

A Guide to Depression, Anxiety and Stress Scale (DASS21): The Dass 21 is 21 item self-report questionnaire designed to measure the severity of a range of symptoms common to both Depression and Anxiety. In complet- 
ing the Dass the participants are required to indicate the presence of a symptom over the previous week. Each item is scored from 0 (did not apply to me at all over the last week) to 3 (applied to me very much or most of the time over the past week). The essential function of the Dass is to assess the severity of the core symptoms of Depression, Anxiety and Stress. The instrument has been standardized for Greek populations (Lovibond \& Lovibond, 1995).

Measurement of salivary cortisol: Measurement of cortisol in saliva 3 times a day for both, intervention and control group (awakeness, 45 minutes later and 12 hours later), before and after intervention, with a special device (salivette) and then laboratory testing.

\subsection{Sample Size}

We randomized 60 participants (30 for the intervention group and 30 for the control group), but the enrolled sample size was smaller. The attrition rate was $20 \%$. Finally the sample size was 54 parents of children with diabetes type 1 .

\subsection{Randomization and Blinding}

The parents deemed eligible at baseline assessment during the ONC visit were randomly assigned to either the intervention or control group, using random numbers generated by an online generator (at in www.random.org). Randomization, baseline and final measurements were not blinded.

\subsection{Statistical Methods}

The continuous variables are expressed mainly in the form of mean \pm standard deviation. In some cases also maximum and minimum values were used. For the discrete variables frequencies and $\%$ frequencies were used.

Primarily in order to test differences between intervention and control groups for the different variables (demographic, patterns, scales-PSS, DASS21 and salivary cortisol) independent samples t-test was used. For relevant comparisons between repeated measurements before-and-after intervention we used the paired t-test.

In the second level comparisons between repeated measurements DASS21, PSS and salivary cortisol were examined by applying analysis of variance with repeated measures (repeated measures ANOVA). In the above ANOVA model also the effects of various factors (e.g. events, gender, age) that affect the scales of anxiety, depression and stress were adjusted.

The correlation between salivary levels and scores was examined using the correlation coefficient of Pearson (Pearson's rho) whereas for the differences-correlations of discrete variables the Pearson's chi-square test was used.

The results were presented using appropriate charts like scatter plots, box-plots and histograms. The analysis was performed using the statistical package IBM SPSS Statistics 20.0. The level of significance was set to $\mathrm{a}=$ 0.05 .

\section{Results}

\subsection{Baseline Analyses}

The demographic characteristics of the two test groups (intervention group and control group) are shown in Table 1. There was no significant difference in the two age groups (intervention and control) $p=0.522$. Participants have similar demographic characteristics in terms of gender, number of children, education level, caring people with disabilities. The only statistical difference was observed among children less than 6 years $(p=0.029)$.

The routine of individuals was assessed by a questionnaire which recorded the frequency of maintenance of an appropriate program for people every day mainly on feeding and sleeping. This routine was followed by people in the $1 / 3$ while no statistically significant difference between those two groups was shown. Other behaviors and habits of the people that are also considered as positive for human, were evaluated in the same manner, and people were asked to rate the feeling of satisfaction of various aspects of their lives. Each person has approximately $40 \%$ of recorded good habits and the level of satisfaction people is rounded approximately to $60 \%$ of satisfaction. For all these three parts of the questionnaire no statistically significant difference appeared between the two groups $(p>0.05)$. 
Considering the life events of both groups there was no significant difference in the background between events low to moderate ( $p=0.777)$, moderate to high $(p=0.610)$ and high to very high $(p=0.336)$ probability illness. We note that events such as death, divorce or separation imprisonment seizure have zero frequency.

\subsection{Primary Endpoint Analyses}

In this section are presented in detail in the form of Tables 2-3 and diagrams differences in scales DASS21 and PSS as measured between intervention and control groups as well as between repetitions.

We observe that among the intervention and control groups no statistically significant difference was shown with respect to the first measurement (background). Specifically, the p-values are 0.468, 0.921, 0.799 and 0.716 for scales DASS21 depression, DASS21 Anxiety, DASS21 Stress and PSS, respectively. Applying the above univariate analysis for the second measurement (end of intervention) differences appeared between scales DASS21 depression $(p=0.044)$, DASS21 stress $(p=0.006)$ and PSS $(p=0.017)$.

Table 1. Demographic characteristics of the examined groups during phase one (background).

\begin{tabular}{|c|c|c|c|}
\hline & $\begin{array}{l}\text { Intervention Group } \\
\qquad(\mathrm{N}=28)\end{array}$ & $\begin{array}{l}\text { Control Group } \\
\qquad(\mathrm{N}=26)\end{array}$ & $p$-value \\
\hline $\begin{array}{l}\text { Age (mean } \pm \text { SD) } \\
\quad[\text { min - max }]\end{array}$ & $\begin{array}{l}40.9 \pm 7.0 \\
{[27-59]}\end{array}$ & $\begin{array}{l}39.73 \pm 6.58 \\
{[29-55]}\end{array}$ & 0.522 \\
\hline Women n (\%) & $18(64,3)$ & $18(69.2)$ & 0.700 \\
\hline Cohabit n (\%) & $28(100,0)$ & $26(100.0)$ & 1.000 \\
\hline $\begin{array}{l}\text { Number of children (mean } \pm \text { SD) } \\
{[\text { [min - max }]}\end{array}$ & $\begin{array}{c}2.9 \pm 1.0 \\
{[1-5]}\end{array}$ & $\begin{array}{c}2.7 \pm 1.3 \\
{[1-6]}\end{array}$ & 0.571 \\
\hline $\begin{array}{c}\text { children under age of } 6 \text { (mean } \pm \text { SD) } \\
\text { [min - max] }\end{array}$ & $\begin{array}{l}0.5 \pm 0.64 \\
{[0-2]}\end{array}$ & $\begin{array}{c}1.1 \pm 1.2 \\
{[0-4]}\end{array}$ & 0.029 \\
\hline Care people with special needs (n \%) & $8(28.6)$ & $9(36.0)$ & 0.563 \\
\hline Education level—high (n \%) & $5(17.9)$ & $4(15.4)$ & 0.808 \\
\hline $\begin{array}{c}\text { Education level—additional years (mean } \pm \text { SD) } \\
\text { [min - max] }\end{array}$ & $\begin{array}{c}1.3 \pm 2.7 \\
{[0-11]}\end{array}$ & $\begin{array}{c}1.5 \pm 2.5 \\
{[0-9]}\end{array}$ & 0.803 \\
\hline \multicolumn{4}{|l|}{ Smoker n (\%) } \\
\hline $\begin{array}{c}\text { Yes } \\
\text { No } \\
\text { Ex-Smoker }\end{array}$ & $\begin{array}{l}10(35.7) \\
11(39.3) \\
10(18.5)\end{array}$ & $\begin{array}{l}14(53.8) \\
9(34.6) \\
3(11.5)\end{array}$ & 0.302 \\
\hline
\end{tabular}

Table 2. PSS and DASS21 scores between the control and intervention groups among repetitions.

\begin{tabular}{|c|c|c|c|c|c|c|}
\hline & \multirow[b]{2}{*}{ DASS21 } & \multicolumn{2}{|c|}{ Intervention Group $(n=28)$} & \multicolumn{2}{|c|}{ Control Group $(n=25)$} & \multirow[b]{2}{*}{$p$-value } \\
\hline & & Mean Value & Standard Deviation & Mean Value & Standard Deviation & \\
\hline & Baseline & 10.0 & 10.3 & 12.0 & 9.6 & 0.468 \\
\hline \multirow[t]{3}{*}{ Depression } & Repeated & 5.6 & 8.8 & 10.6 & 9.6 & 0.044 \\
\hline & $\mathrm{P}(\mathrm{ANOVA})$ & & & & & \\
\hline & Baseline & 8.5 & 11.5 & 8.2 & 6.4 & 0.921 \\
\hline \multirow[t]{3}{*}{ Anxiety } & Repeated & 5.3 & 8.4 & 8.0 & 7.0 & 0.202 \\
\hline & $\mathrm{P}$ (ANOVA) & & & & & \\
\hline & Baseline & 14.8 & 11.1 & 15.5 & 9.6 & 0.799 \\
\hline \multirow[t]{3}{*}{ Stress } & Repeated & 8.1 & 7.2 & 14.8 & 10.6 & 0.006 \\
\hline & $\mathrm{P}(\mathrm{ANOVA})$ & & & & & \\
\hline & Baseline & 27.4 & 13.7 & 28.5 & 8.5 & 0.716 \\
\hline \multirow[t]{2}{*}{ PSS } & Repeated & 22.4 & 8.9 & 28.4 & 9.1 & 0.017 \\
\hline & P (ANOVA) & & & & & \\
\hline
\end{tabular}


Table 3. Cortisol levels and comparison between repetitions.

\begin{tabular}{|c|c|c|c|c|c|c|}
\hline & & \multicolumn{2}{|c|}{ Intervention Group (n = 27) } & \multicolumn{2}{|c|}{ Control Group (n = 14) } & \multirow[b]{2}{*}{$p$-value } \\
\hline & & Mean Value & Standart Deviation & Mean Value & Standart Deviation & \\
\hline Cortisol & 1st Measurement-Awakening & -0.27 & 0.27 & -0.27 & 0.15 & 0.922 \\
\hline \multirow{3}{*}{ Baseline } & 2nd Measurement—45 Minutes & -0.25 & 0.32 & -0.26 & 0.22 & 0.868 \\
\hline & $3 \eta$ Measurement -2 hours & -0.65 & 0.23 & -0.72 & 0.17 & 0.429 \\
\hline & p (ANOVA) & \multicolumn{4}{|c|}{0.746} & \\
\hline Cortisol & 1st Measurement-Awakening & -0.17 & 0.16 & -0.24 & 0.19 & 0.181 \\
\hline \multirow{3}{*}{ Repetition } & 2nd Measurement—45 Minutes & -0.28 & 0.20 & -0.35 & 0.22 & 0.302 \\
\hline & $3 \eta$ Measurement-12 hours & -0.53 & 0.20 & -0.64 & 0.17 & 0.062 \\
\hline & $\mathrm{p}(\mathrm{ANOVA})$ & \multicolumn{4}{|c|}{0.789} & \\
\hline
\end{tabular}

Based on the results of ANOVA repeat measurements a difference in scale DASS21 stress $(p=0.024)$ revealed and there is a tendency for difference $(p=0.060)$ for the scale PSS $(0.050<p=0.060<0.100)$.

Note. The PSS is a self-reported 14-item measure of the degree to which situations in an individual's life are appraised as stressful. For this purpose, respondents rated the frequency of their feelings and thoughts over the previous month in a five-point Likert type scale (from $0=$ never to $4=$ very often). There are seven positive and seven negative items and the total score was calculated by summing up each score after reversing all the positive items (min. total score $=0$, max. total score $=56$ ). Higher scores indicate higher level of perceived stress by the individual during the last month. PSS measurement was performed at the beginning of the trial and at the end of the 8-week of follow-up (Andreou et al., 2011; Cohen, Mermelstein, \& Kamarck, 1983). The Dass 21 is 21 item self-report questionnaire designed to measure the severity of a range of symptoms common to both Depression and Anxiety. In completing the Dass the participants are required to indicate the presence of a symptom over the previous week. Each item is scored from 0 (did not apply to me at all over the last week) to 3 (applied to me very much or most of the time over the past week). The essential function of the Dass is to assess the severity of the core symptoms of Depression, Anxiety and Stress. The instrument has been standardized for Greek populations (Lovibond \& Lovibond, 1995).

\subsection{Levels of Salivary Cortisol}

The results of salivary cortisol in the studied groups are presented in this section. The logarithm of salivary cortisol of values was used. No statistically significant differences between control group and intervention group at baseline and at repetition. The results were tested for cortisol comparisons between groups using t-test and between the three measurements at baseline (ANOVA repeated measurements) and at repetition (ANOVA repeated measures).For the estimation of the effect of the intervention (CD) the differences in the levels of the first measurement between the intervention and control groups at baseline and at repetition were tested. Although there is an increase in cortisol levels in the intervention group before and after the intervention (while the control group remained constant) the difference is not statistically significant $(p=0.447)$.Similar results were observed when tested at the second and the third measurement $(p=0.579$ and $p=0.489)$ respectively.

\subsection{Evaluation of Health through the Scale HL (Health Locus) and Symptom Scores}

Considering the baseline measurements showed no difference between the scales HL and symptoms except scale HL Chance $(p=0.047)$. Also the repeated measurements ANOVA showed no statistically significant difference between the HL scores before and after and between intervention groups-control.

\subsection{Secondary Endpoint Analyses}

In this section we examine using multiple regression the effect on the scales of DASS21 depression, anxiety and stress variables that may affect the process of intervention. Created three new variables to calculate the change in sub scales DASS21 = DASS21 at repetition - DASS21 at baseline for depression, anxiety and stress.

The application of linear regression was performed at the presence of variables: intervention, age, gender, 
care of persons with special needs, life events (score) in the baseline, scale DASS1 depression in the baseline, and the three HL scales in the baseline. We observe that there is a "lowering effect" of depression of about 5 points (4.7) at the scale of depression DASS21 when intervention. The curve fit was relatively good $\mathrm{R}^{2}=0.315$. Corresponding task was to scale DASS21 anxiety. We also observe that there is a tendency to reduce the impact of stress in the range -3.4 units DASS21 anxiety when intervention. The curve fit was relatively good $\mathrm{R}^{2}=$ 0.444. The effect of the intervention has reduced by about seven points scale stress DASS21. The curve fit was relatively good $\mathrm{R}^{2}=0.529$ (Figure 1 ).

\section{Discussion}

We conducted this pilot randomized controlled trial study to assess stress management treatment comprising of an 8-week relaxation training program (relaxation breathing and progressive muscle relaxation, RB-PMR) in parents of children with diabetes type 1 . Our results can be summarized as the following: 1) RB-PMR practice significantly decreased Perceived Stress and symptoms of Depression and Anxiety. We observe that there is a "lowering-effect" of depression of about 5 points (4.7) at the scale of depression DASS21 when intervention. The curve fit was relatively good $R^{2}=0.315$ and there is a tendency to reduce the impact of stress in the range -3.4 units DASS21 anxiety when intervention. The curve fit was relatively good $\mathrm{R}^{2}=0.444$. The effect of the intervention has reduced by about seven points scale anxiety DASS21. The curve fit was relatively good $\mathrm{R}^{2}=$ 0.529 . We also observed that among the intervention and control groups no statistically significant difference was shown with respect to the first measurement (background). Specifically, the p-values are 0.468, 0.921, 0.799 and 0.716 for scales DASS21 depression, DASS21 Anxiety, DASS21 Stress and PSS, respectively. Applying the above univariate analysis for the second measurement (end of intervention) differences appeared between scales DASS21 depression $(p=0.044)$, DASS21 stress $(p=0.006)$ and PSS $(p=0.017)$. Based on the results of ANOVA repeat measurements a difference in scale DASS21 stress $(p=0.024)$ revealed and there is a tendency for difference $(p=0.060)$ for the scale PSS $(0.050<p=0.060<0.100)$. 2) The results were tested for cortisol comparisons between groups using t-test and between the three measurements at baseline (ANOVA repeated measurements) and at repetition (ANOVA repeated measures). For the estimation of the effect of the intervention (CD) the differences in the levels of the first measurement between the intervention and control groups at baseline and at repetition were tested. Although there is an increase in cortisol levels in the intervention group before and after the intervention (while the control group remained constant) the difference is not statistically significant ( $p=0.447$ ) (Figure 2). Similar results were observed when tested at the second and the third measurement ( $p=0.579$ and $p=0.489$ ) respectively. 3 ) Considering the baseline measurements showed no difference between the scales HL and symptoms except scale HL Chance $(p=0.047)$. Also the repeated measurements ANOVA showed no statistically significant difference between the HL scores before and after and between intervention groups-control.

It is acknowledged that this study has a number of limitations. Firstly, our entire primary outcome measures were based on self-administered self-reports as opposed to objective clinical assessments. Our laboratory results (increase cortisol measures for the intervention group) can be explained by participant's behavior. Participants did cortisol's measures at their home under researcher's constructions. It was likely to fail to meet the strict instructions of researcher and drank coffee for example before the first or second measurement. It is known that coffee increases circulating cortisol concentrations in healthy people (Gavrieli et al., 2011). Furthermore, parents in the intervention group would be more prone to ameliorate the final measurements or underestimate symptoms, to positively assist study results or to satisfy their pediatricians. To minimize this source of bias, we had organized weekly telephone communication with patients of both groups, thus the sense of offer was fostered in all patients. Moreover, the small sample of our study may be explained by the mileage distance between the pediatric-diabetologist section of the general hospital of the remaining counties of the island. Researcher visited several times two of the counties of island but due to cost and time it was not possible to cover all of them. In addition, the time limit set for the intervention was eight weeks, which is a reasonable time to investigate the psychological symptoms but quite restrictive.

Finally, by comparing our results with the results of other similar surveys, we understand that parents of children with juveline diabetes experiencing severe symptoms of stress, anxiety and depression, but find ways to manage them, although as we mentioned the use of relaxation techniques not yet document in the literature (Streisand et al., 2005). 


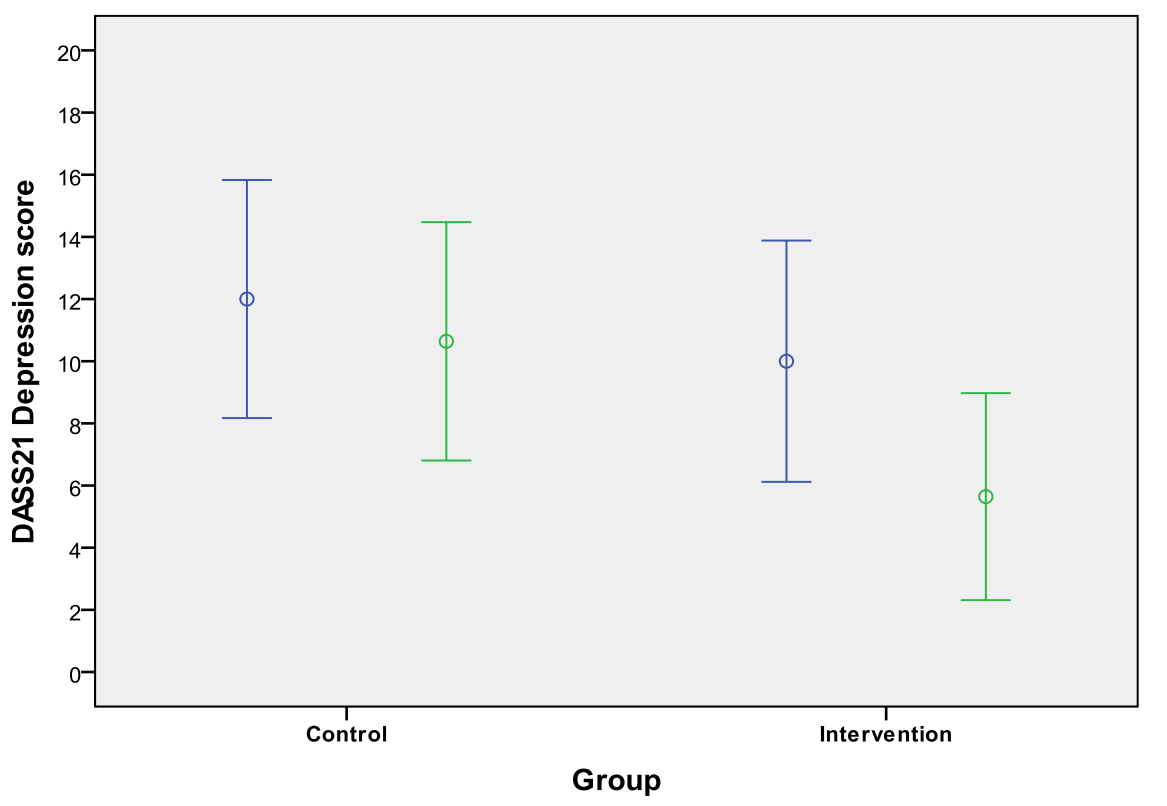

I DASS21 Depression before

I DASS21 Depression after

Figure 1. Scale Stress DASS 21 for the control and intervention groups at baseline and at repetition.

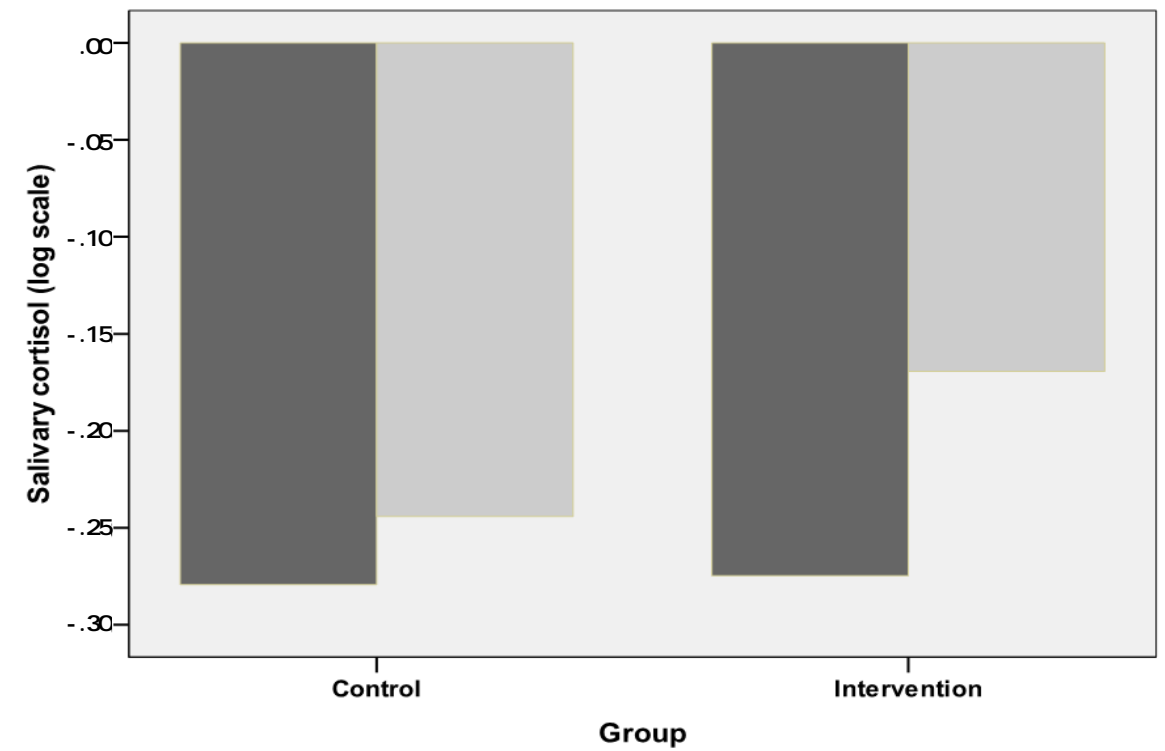

Salivary cortisol
before
Salivary cortisol after

Figure 2. Change levels first measurement (morning) salivary cortisol between the groups before and after.

\section{Conclusion}

In sum, we provide evidence that stress management in parents of children with diabetes type 1 may merit benefits of both physical and psychological well-being. Future studies should extend this preliminary finding using greater sample sizes, examining other similar techniques and measuring more objective laboratory (e.g. measuring cortisol in blood) or clinical (e.g. counseling or psychotherapy) outcomes. We think that simple relaxation techniques, such as RB-PMR characterized by a higher administration and practice feasibility, should be deemed 
as highly cost-effective, non-pharmaceutical treatments in everyday clinical practice.

\section{Conflict of Interest}

All the authors declare that they have no conflict of interest.

\section{References}

Abidin, R. (1995). Parenting Stress Index (3rd ed.). Odessa, FL: Psychological Assessment Resources, Inc.

Andreou, E., Alexopoulos, E. C., Lionis, C., Varvogli, L., Gnardellis, C., et al. (2011). Perceived Stress Scale: Reliability and Validity Study in Greece. International Journal of Environmental Research, 8, 3287-3298. http://dx.doi.org/10.3390/ijerph8083287

Barakat, L. P., Patterson, C., Weinberger, B., Simon, K., Gonzalez, E. R., \& Dampier, C. (2007). A Prospective Study of the Role of Coping and Family Functioning in Health Outcomes for Adolescents with Sickle Cell Disease. Journal of Pediatric Hematology Oncology, 29, 752. http://dx.doi.org/10.1097/MPH.0b013e318157fdac

Baughcum, A. E., Johnson, S. B., Carmichael, S. K., Lewin, A. B., She, J.-X., \& Schatz, D. A. (2005). Maternal Efforts to Prevent Type 1 Diabetes in At-Risk Children. Diabetes Care, 28, 916-921.

Chrousos, G. P. (2009). Stress and Disorders of the Stress System. Nature Reviews Endocrinology, 5, 374-381. http://dx.doi.org/10.1038/nrendo.2009.106

Cohen, S., \& Kessler, R. C. (1997). Measuring Stress. Oxford: Oxford University Press.

Colletti, J. M., Wolfe-Christensen, C., Carpentier, M. Y., Page, M. C., McNall-Knapp, R. Y., Meyer, W. H., \& Mullins, L. L. (2008). The Relationship of Parental Overprotection, Perceived Vulnerability, and Parenting Stress to Behavioral, Emotional, and Social Adjustment in Children with Cancer. Pediatric Blood \& Cancer, 51, 269-274. http://dx.doi.org/10.1002/pbc.21577

Cummings, E. M., Greene, A. L., \& Karraker, K. H. (1991). Life-Span Developmental Psychology: Perspectives on Stress and Coping (p. 92). Hillsdale, NJ: Lawrence Erlbaum Associates, Inc.

Daneman, D. (2005). Early Diabetes-Related Complications in Adolescents. Hormone Research, 63, 75-85.

Dykens, E. M., Fisher, M. H., Taylor, J. L., Lambert, W., \& Miodrag, N. (2014). Reducing Distress in Mothers of Children with Autism and other Disabilities: A Randomized Trial. Pediatrics, 134, e454-e463.

http://dx.doi.org/10.1542/peds.2013-3164

Esterling, B. A., Kiecolt-Glaser, J. K., \& Glaser, R. (1996). Psychosocial Modulation for Cytokine-Induced Natural Killer Cell Activity in Older Adults. Psychosomatic Medicine, 58, 264-272. http://dx.doi.org/10.1097/00006842-199605000-00010

Hilliard, M. E., Monaghan, M., Cogen, F. R., \& Streisand, R. (2010). Parent Stress and Child Behavior among Young Children with Type 1 Diabetes. Child: Care, Health and Development, 37, 224-232. http://dx.doi.org/10.1111/j.1365-2214.2010.01162.x

Jaser, S. S., \& Grey, M. (2010). A Pilot Study of Observed Parenting and Adjustment in Adolescents with Type 1 Diabetes and Their Mothers. Journal of Pediatric Psychology, 35, 738-747. http://dx.doi.org/10.1093/jpepsy/jsp098

Kiecolt-Glaser, J. K., Marucha, P. T., Malarkey, W. B., Mercado, A. M., \& Glaser, R. (1995). Slowing of Wound Healing by Psychological Stress. The Lancet, 346, 1194-1196. http://dx.doi.org/10.1016/S0140-6736(95)92899-5

Kunz-Ebrecht, S. R., Kirschbaum, C., Marmot, M., \& Steptoe, A. (2004). Differences in Cortisol Awakening Response on Workdays and Weekends in Women and Men from the Whitehall II Cohort. Psychoneuroendocrinology, 29, 516-528.

LeRoy, A. (2013). Exhaustion, Anger of Caregiving Get a Name. Turner Broadcasting System, Inc.

Lovibond, S. H., \& Lovibond, P. F. (1995). Manual for the Depression Anxiety Stress Scales (2nd ed.). Sydney: Psychology Foundation of Australia.

McEwen, B. S. (1998). Stress, Adaptation, and Disease: Allostasis and Allostatic Load. Annals of the New York Academy of Sciences, 840, 33-44. http://dx.doi.org/10.1111/j.1749-6632.1998.tb09546.x

Mullins, L. L., Fuemmeler, B. F., Hoff, A., Chaney, J. M., Van Pelt, J., \& Ewing, C. A. (2004). The Relationship of Parental Overprotection and Perceived Child Vulnerability to Depressive Symptomatology in Children with Type 1 Diabetes Mellitus: The Moderating Influence of Parenting Stress. Children's Health Care, 33, 21-34.

http://dx.doi.org/10.1207/s15326888chc3301_2

Mullins, L. L., Wolfe-Christensen, C., Pai, A. L. H., Carpentier, M. Y., Gillaspy, S., Cheek, J., \& Page, M. (2007). The Relationship of Parental Overprotection, Perceived Child Vulnerability, and Parenting Stress to Uncertainty in Youth with Chronic Illness. Journal of Pediatric Psychology, 32, 973-982. http://dx.doi.org/10.1093/jpepsy/jsm044 
Nicholson, T. R., Taylor, J. P., Gosden, C., Trigwell, P., \& Ismail, K. (2009). National Guidelines for Psychological Care in Diabetes: How Mindful Have We Been? Diabetic Medicine, 26, 447-450. http://dx.doi.org/10.1111/j.1464-5491.2009.02701.x

Pires da Rocha, M. C., Figueiredo De Martino, M. M., Grassi-Kassisse, D. M., \& Luiz de Souza, A. (2013). Stress among Nurses: An Examination of Salivary Cortisol Levels on Work and Day Off. Revista da Escola de Enfermagem USP, 47, 1187-1194. http://dx.doi.org/10.1590/S0080-623420130000500025

Powers, S. W., Byars, K. C., Mitchel, M. J., Patton, S. R., Standiford, D. A., \& Dolan, L. M. (2002). Parent Report of Mealtime Behavior and Parenting Stress in Young Children with Type 1 Diabetes and in Healthy Control Subjects. Diabetes Care, 25, 313-318.

Schulz, R., \& Beach, S. R. (1999). Caregiving as a Risk Factor for Mortality. The Journal of the American Medical Association, 282, 2215-2219. http://dx.doi.org/10.1001/jama.282.23.2215

Streisand, R., Braniecki, S., Tercyak, K. P., \& Kazak, A. E. (2001). Childhood Illness-Related Parenting Stress: The Pediatric Inventory for Parents. Journal of Pediatric Psychology, 26, 155-162. http://dx.doi.org/10.1093/jpepsy/26.3.155

Streisand, R., Swift, E., Wickmark, T., Chen, R., \& Holmes, C. S. (2005). Pediatric Parenting Stress among Parents of Children with Type 1 Diabetes: The Role of Self-Efficacy, Responsibility and Fear. Journal of Pediatric Psychology, 30, 513-521. http://dx.doi.org/10.1093/jpepsy/jsi076

Sulkers, E., Tissing, W. J. E., Brinksma, A., et al. (2014). Providing Care to a Child with Cancer: A Longitudinal Study on the Course, Predictors and Impact of Caregiving Stress during the First Year after Diagnosis. Psycho-Oncology, 24, 318324.

Sullivan-Bolyai, S., Knafl, K., Tamborlane, W., \& Grey, M. (2004). Parent’s Reflections on Managing Their Children Diabetes with Insulin Pumps. Journal of Nursing Scholarship, 36, 316-323. http://dx.doi.org/10.1111/j.1547-5069.2004.04058.x

Thompson, R. J., \& Gustafson, K. E. (1996). Adaptation to Chronic Childhood Illness. Washington DC: American Psychological Association. http://dx.doi.org/10.1037/10188-000

Thompson, R. J., Gil, K. M., Burbach, D. J., Keith, B. R., \& Kinney, T. R. (1993). Psychological Adjustment of Mothers of Children and Adolescents with Sickle Cell Disease: The Role of Stress, Coping Methods, and Family Functioning. Journal of Pediatric Psychology, 18, 549-559. http://dx.doi.org/10.1093/jpepsy/18.5.549

Thompson, R. J., Gustafson, K. E., Hamlett, K. W., \& Spock, A. (1992). Psychological Adjustment of Children with Cystic Fibrosis: The Role of Child Cognitive Processes and Maternal Adjustment. Journal of Pediatric Psychology, 17, 741-755. http://dx.doi.org/10.1093/jpepsy/17.6.741

Tsiouli, E., Alexopoulos, E. C., Stefanaki, C., Darviri, C., \& Chrousos, G. P. (2013). Effects of Diabetes-Related Family Stress on Glycemic Control in Young Patients with Type 1 Diabetes: Systematic Review. Canadian Family Physician, 59, 143-149.

Vehik, K., \& Dabelea, D. (2010). The Changing Epidemiology of Type 1 Diabetes: Why Is It Going through the Roof? Diabetes/Metabolism Research and Reviews, 27, 3-13.

Wallston, K. A., Wallston, B. S., \& DeVellis, R. (1978). Development of the Multidimensional Health Locus of Control Scale. Health Education Monographs, 6, 160-170. http://dx.doi.org/10.1177/109019817800600107

Warram, J. H. (2012). Genetics and Diabetes. Boston, MA: Joslin Diabetes Center and Joslin Clinic.

Weinger, K., \& Jacobson, A. M. (2001). Psychosocial and Quality of Life Correlates of Glycemic Control during Intensive Treatment of Type 1 Diabetes. Patient Education and Counseling, 42, 123-131. http://dx.doi.org/10.1016/s0738-3991(00)00098-7

Wennick, A., \& Hallstrom, I. (2006). Swedish Familie’s Lived Experience When a Child Is First Diagnosed as Having Insulin-Dependent Diabetes Mellitus. Journal of Family Nursing, 12, 368-389.

Worral-Davies, A., Owens, D., Holland, P., \& Haigh, D. (2001). The Effect of Parental Expressed Emotion on Glycaemic Control in Children with Type 1 Diabetes. Parental Expressed Emotion and Glycaemic Control in Children. Journal of Psychosomatic Research, 52, 107-113. 